\title{
First record of the Kermadec Clingfish, Flexor incus Conway, Stewart \& Summers, 2018 (Gobiesocidae), from New Caledonia and Australia
}

\author{
Kyoji Fujiwara $^{1}$, Kevin W. Conway ${ }^{2,3}$, Hiroyuki Motomura ${ }^{3,4}$ \\ 1 The United Graduate School of Agricultural Sciences, Kagoshima University, Kagoshima, Japan • KF: kyojifujiwara627@yahoo.co.jp \\ 2 Department of Ecology and Conservation Biology and Biodiversity Research and Teaching Collections, Texas A\&M University, College Sta- \\ tion, USA・KWC: kevin.conway@tamu.edu \\ 3 Research Associate, Ichthyology, Australian Museum Research Institute, NSW, Australia •HM: motomura@kaum.kagoshima-u.ac.jp \\ 4 The Kagoshima University Museum, Kagoshima, Japan \\ * Corresponding author
}

\begin{abstract}
Two specimens (17.1 and $29.1 \mathrm{~mm}$ standard length) of Flexor incus Conway, Stewart \& Summers, 2018 (Gobiesocidae) were collected from New Caledonia and Lord Howe Island, Australia. The species and genus were originally described on the basis of 15 specimens from the Kermadec Islands, New Zealand, where the genus has been considered endemic. The two specimens reported herein represent the first records of $F$. incus from New Caledonia and Australia.
\end{abstract}

\section{Keywords}

Diademichthyinae, geographic distribution, Pacific Ocean, range extension, Tasman Sea

Academic editor: Zeehan Jaafar | Received 4 January 2021 | Accepted 20 April 2021 | Published 14 May 2021

Citation: Fujiwara K, Conway KW, Motomura H (2021) First record of the Kermadec Clingfish, Flexor incus Conway, Stewart \& Summers, 2018 (Gobiesocidae), from New Caledonia and Australia. Check List 17 (3): 769-773. https://doi.org/10.15560/17.3.769

\section{Introduction}

The family Gobiesocidae is a moderate-sized fish family, commonly called clingfishes because all members of the family, except for the shore eel genus Alabes Cloquet, 1816, have a well-developed ventral adhesive disk with which they adhere tightly to the substrate (Briggs 1955; Conway et al. 2020). Most members of the family inhabit intertidal and subtidal zones in the Atlantic and Indo-Pacific oceans, and a small number of species occur in deeper waters down to $570 \mathrm{~m}$ or in freshwater streams in the neotropics (Briggs 1955; Conway et al. 2017a; Hastings and Conway 2017). Currently, the family contains 185 valid species of 51 genera (Fricke et al.
2021). However, taxonomic study on the family continues to result in the description of new taxa (four new genera and 22 new species have been described since 2015) (Fricke et al. 2021).

As part of an ongoing taxonomic study of the Gobiesocidae, we examined unidentified material from New Caledonia and Australia (Lord Howe Island) held in the ichthyology collections of the National Museum of Natural History (Washington, DC) and the Australian Museum (Sydney), respectively. Subsequently, these specimens were identified as Flexor incus Conway, Stewart \& Summers, 2018, originally described as a new 
genus and species on the basis of 15 specimens from the Kermadec Islands, New Zealand. Because additional specimens of the species have not been recorded until now, the present specimens, reported in this study, represent a significant distribution range extension for $F$. incus into the southwestern Pacific Ocean. Comparative comments on Flexor and the similar, potentially closely related genera Pherallodus and Propherallodus are also provided.

\section{Methods}

Counts and measurements followed Conway et al. (2018a). Measurements are expressed as a percentage of standard length (SL) or head length (HL), respectively. Disc terminology follows Briggs (1955: fig. 1). Head sensory pore terminology follows Shiogaki and Dotsu (1983: fig. 1) and Conway et al. (2017b: fig. 1). Those regions were observed using versatile staining with Cyanine Blue (Saruwatari et al. 1997). The distributional map was prepared using GMT 5.3.1, with data from GSHHG (Wessel and Smith 1996). Institutional codes followed Sabaj (2020).

Comparative material examined. Flexor incus: holotype and 14 paratypes, 14.0-27.2 mm SL, listed in Conway et al. (2018a). Pherallodus indicus (Weber, 1913): CMNHZF 11050, 19.5 mm SL, KAUM-I. 20722, 26.2 mm SL, Boso Peninsula, Chiba, Japan; KAUM-I. 40072, 14.3 mm SL, Yoron Island, Amami Islands, Ryukyu Islands, Japan. Propherallodus smithi (Briggs, 1955): CAS 131349, holotype, $18.5 \mathrm{~mm}$ SL, Durban, South Africa.

\section{Results}

New records (Fig. 1). NEW CALEDONIA - Loyalty Islands • north of Wenyook Island; $20^{\circ} 26^{\prime} 06^{\prime \prime} \mathrm{S}, 166^{\circ} 28^{\prime}$ 30"E; 0.6-3.6 m depth; 17. XI. 1991; J. Williams and M. Kulbicki; USNM 322448, $29.1 \mathrm{~mm}$ SL.

AUSTRALIA - New South Wales - Lord Howe Island, North Head; $31^{\circ} 32^{\prime} \mathrm{S}, 159^{\circ} 04^{\prime} \mathrm{E}$; D. Hoese; AMS I. 17424-003, $20.8 \mathrm{~mm}$ SL.

Identification. Morphometrics data on the two specimens from New Caledonia and Australia (Fig. 2) are provided in Table 1 . The present specimens agree closely with Conway et al. (2018a), the original description of $F$. incus, in having the following characters: 9 or 10 dorsalfin rays; 9 anal-fin rays (except for USNM 322448); 24 pectoral-fin rays (except for AMS I. 17424-003); upperjaw teeth incisiviform, compressed laterally, with hooklike tips strongly curved posteriorly (ca. 90), except for symphysis with 2 or 3 slightly curved conical teeth; lower-jaw teeth with pointed conical tips, inner surface slightly curved; small oval opening between premaxillae present; head sensory canal pores well developed, including 2 nasal, 2 lacrimal, 2 postorbital, and 3 preopercular pores; mandibular pores absent; gill membranes free from isthmus; pelvic fins and pectoral-girdle elements forming a circular, "double" adhesive disc; disc regions $\mathrm{A}, \mathrm{B}$, and $\mathrm{C}$ with flattened papillae (damaged in AMS I. 17424-003), anterior part of disc region A with 3 rows of papillae across center, disc region B with 4 rows of papillae, and disc region D without papillae (Fig. 3).

Counts of anal- and pectoral-fin rays differ slightly between the specimens presented herein and those of the type series [7 anal-fin rays (USNM 322448) and 22 pectoral-fin rays (AMS I. 17424-003) vs. 8 or 9 and 24 or 25 , respectively in the original description]. However, these differences are regarded here as intraspecific variations of $F$. incus as similar variations have been reported

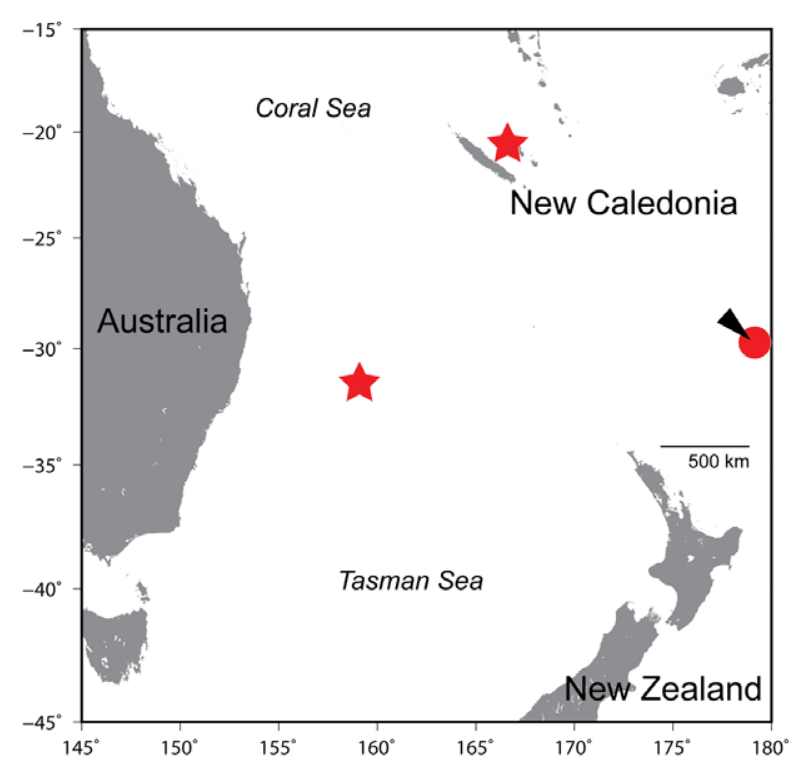

Figure 1. Distribution records of Flexor incus. Stars and circle indicate new and previous records, respectively. Arrowhead indicates type locality.

Table 1. Morphometric measurements of Flexor incus from New Caledonia (USNM 322448), Australia (AMS I. 17424-003) and New Zealand (Conway et al., 2018a; $n=7$ ).

\begin{tabular}{lccc}
\hline & $\begin{array}{c}\text { USNM } \\
\mathbf{3 2 2 4 4 8}\end{array}$ & $\begin{array}{c}\text { AMS I. } \\
\mathbf{1 7 4 2 4 - 0 0 3}\end{array}$ & $\begin{array}{c}\text { Conway } \\
\text { et al. 2018a }\end{array}$ \\
\hline Standard length (mm; SL) & 29.1 & 20.8 & $16.9-27.2$ \\
\hline In \% of SL & & & \\
Head length (HL) & 31.0 & 28.7 & $29.4-34.5$ \\
Body depth & 15.3 & 14.6 & $10.0-14.9$ \\
Predorsal length & 75.4 & 69.6 & $73.3-82.2$ \\
Preanal length & 74.2 & 69.6 & $72.6-77.7$ \\
Preanus length & 57.9 & 57.3 & $60.7-63.0$ \\
Anus to disc & 15.6 & 19.9 & $14.1-18.6$ \\
Anus to anal fin & 13.7 & 12.3 & $8.0-9.7$ \\
Caudal-peduncle length & 10.3 & 8.8 & $8.0-10.1$ \\
Caudal-peduncle depth & 10.7 & 9.9 & $8.2-11.1$ \\
Disc length & 19.2 & 17.0 & $17.8-26.0$ \\
Disc width & 15.9 & 15.8 & $16.3-20.1$ \\
\hline In \% of HL & & & \\
Head depth at orbit & 30.9 & 39.8 & $25.9-34.8$ \\
Head width at orbit & 48.7 & 49.0 & $42.6-51.9$ \\
Head width at widest point & 60.2 & 69.4 & $52.9-67.3$ \\
Interorbital width & 22.3 & 26.0 & $19.5-23.1$ \\
Snout length & 30.6 & 26.5 & $28.1-36.5$ \\
Eye diameter & 22.1 & 22.4 & $17.2-22.2$ \\
\hline
\end{tabular}




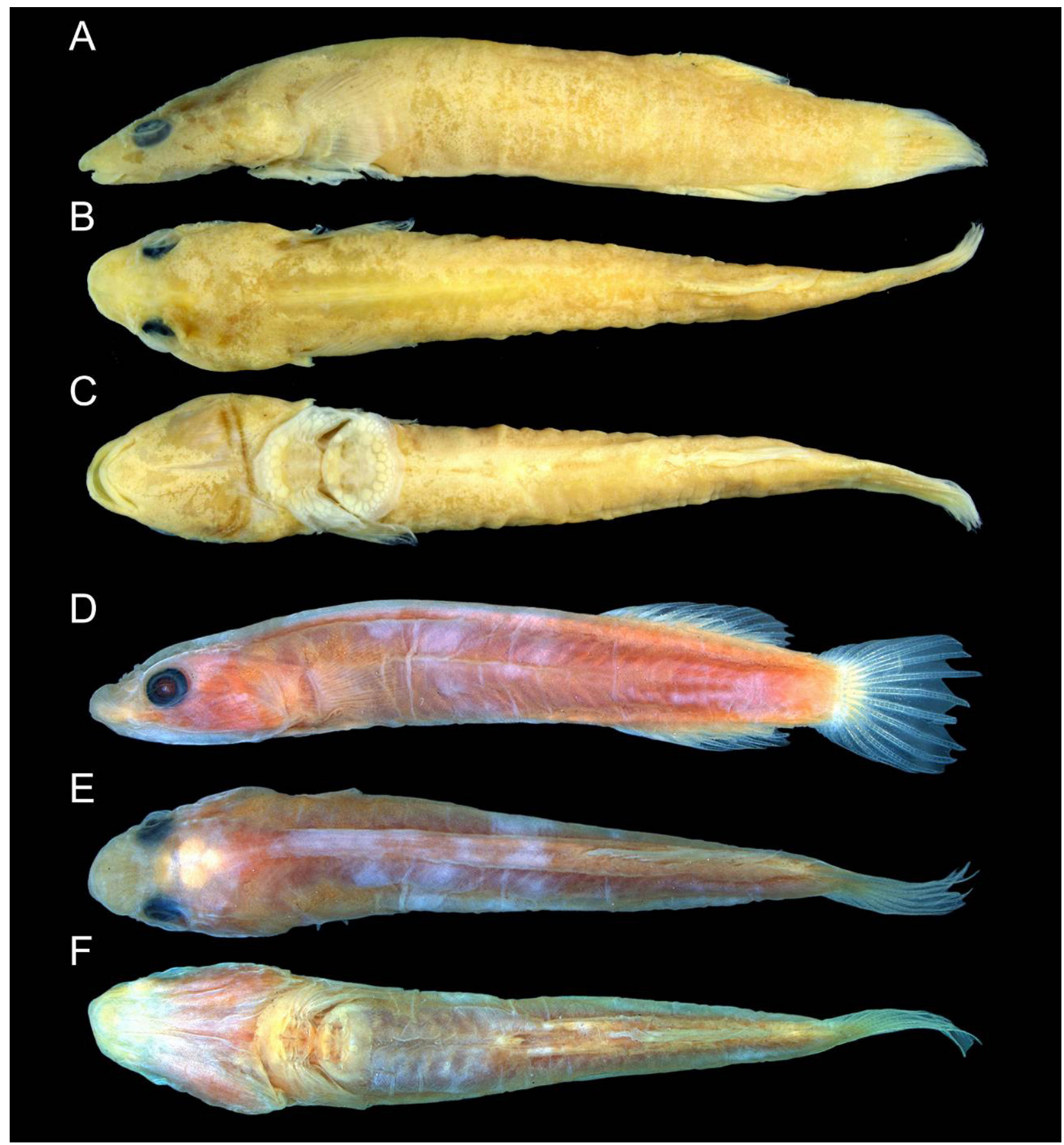

Figure 2. Preserved specimens of Flexor incus. A-C. USNM 322448, $29.1 \mathrm{~mm} \mathrm{SL,} \mathrm{north} \mathrm{of} \mathrm{Wenyook} \mathrm{Island,} \mathrm{Loyalty} \mathrm{Islands,} \mathrm{New} \mathrm{Caledonia.}$ D-F. AMS I. 17424-003, 17.1 mm SL, North Head, Lord How Island, New South Wales, Australia. A, D. Lateral views. B, E. Dorsal view. C, F. Ventral view.

in other gobiesocid genera (e.g., Aspasma ubauo Fujiwara and Motomura 2019). In addition, Conway et al. (2018a) described 2 or 3 rows of papillae on disc region $\mathrm{C}$ whereas only a single row of papillae was confirmed in USNM 322448 (Fig. 3). This discrepancy may be related to papillae loss, which can occur easily during collection leaving no trace (Fujiwara and Motomura 2018a).

\section{Discussion}

Flexor incus was described as a new genus and species on the basis of 15 specimens from the Kermadec Islands of New Zealand. In the original description (Conway et al. 2018a), F. incus was reported from only two islands within the Kermadec archipelago, including Raoul Island (type locality) and L'Esperance Rock, and no additional records of the species have been reported until now. The specimens reported herein, collected from Loyalty Islands and Lord Howe Island, represent the first records of $F$. incus from New Caledonia and Australia, respectively. This suggests that the species possibly has a wider distribution in the southwestern Pacific Ocean and Tasman Sea (Fig. 1). Interestingly, except for the deep-water clingfish Kopua nuimata Hardy, 1984, all tidal and subtidal species of clingfishes inhabiting the 


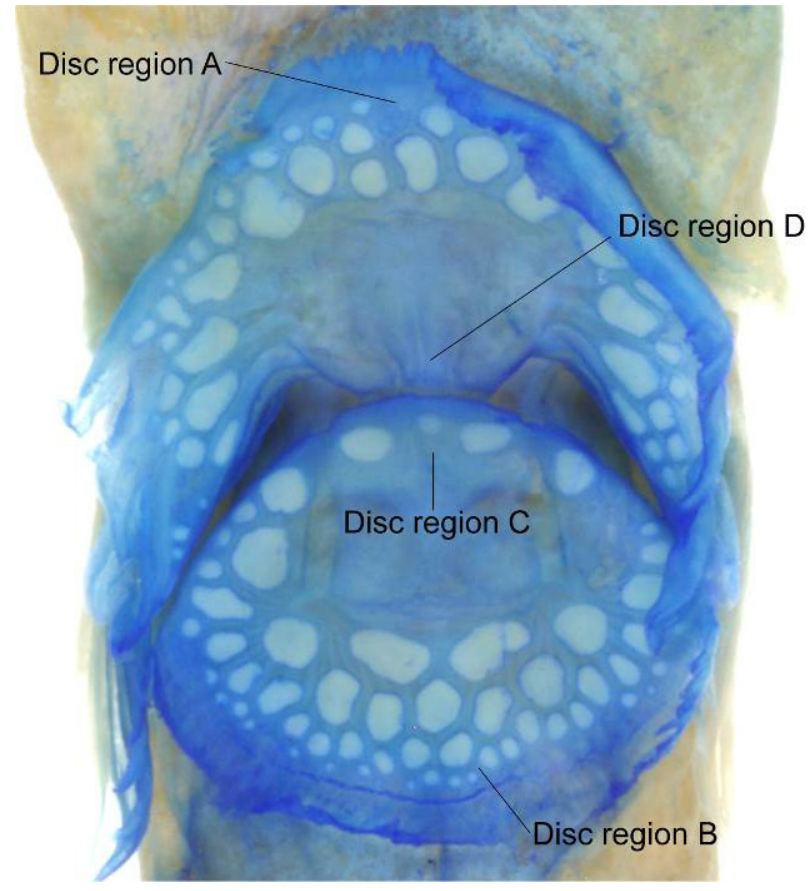

Figure 3. Ventral adhesive disc (cyanine stained) of Flexor incus, USNM 322448, $29.1 \mathrm{~mm}$ SL.

main islands of New Zealand (12 species representing 8 genera) are endemic to this region (Stewart 2015; Conway et al. 2017b, 2018b; Fujiwara and Motomura 2020). Although the Kermadec Islands are included in New Zealand waters, these islands are located far from the relatively well-surveyed main islands and it is unlikely that $F$. incus is present beyond the Kermadec Islands in New Zealand waters.

In their original description of $F$. incus, Conway et al. (2018a) pointed out that the higher classification of clingfishes proposed by Briggs (1955) may require revision. More recently, the classification scheme of Briggs (1955) was revised by Conway et al. (2020), who recognized nine subfamilies in the Gobiesocidae based on the results of a molecular phylogenetic investigation. According to them, the monotypic genus Flexor is assigned to the subfamily Diademichthyinae, which they expanded to include several additional genera formerly included in the Aspasminae, Diplocrepinae, and Protogobiesocinae by Briggs (1955) and Fricke et al. (2016). Although Flexor was recovered as the sister taxon to Aspasmichthys ciconiae (Jordan \& Fowler, 1902) in Conway et al.'s (2020) study, the former is superficially similar to Pherallodus Briggs 1955 [including Pherallodus indicus (Weber, 1913)] and Propherallodus Shiogaki \& Dotsu 1983 [including Propherallodus briggsi Shiogaki \& Dotsu, 1983, Propherallodus longipterus Fujiwara \& Motomura, 2018b, and Propherallodus smithi (Briggs, 1955)]. These three genera can be distinguished from other members of the Diademichthyinae sensu Conway et al. (2020) in having a "double" adhesive disc (sensu Briggs 1955) and gill membranes free from the isthmus. Flexor differs from Pherallodus and Propherallo$d u s$ by the teeth shape in both jaws, disc papillae (also see below), and head sensory canal pores (see Conway et al. 2018a: 95). Papillae are present across the center of region A and C in Flexor (Fig. 3; Conway et al. 2018a: fig. 9A) whereas papillae are said to be absent from the center of both region A and C in Pherallodus (Shiogaki and Dotsu 1983). Examination of specimens of Pherallodus indicus in this study confirmed the absence of papillae from the center of region A as described by Shiogaki and Dotsu (1983) but papillae are present at the center of region C, as in Flexor. Compared with Pherallodus and Propherallodus, Flexor exhibits fewer rows of papillae on disc region B [4 or 5 rows in Flexor (Fig. 3; Conway et al. (2018a) vs. 5-7 (usually 6) in Pherallodus and Propherallodus (Shiogaki and Dotsu 1983; Fujiwara and Motomura 2018b; this study].

\section{Acknowledgements}

We are grateful to A. Hay, S. Reader, and M. McGrouther (AMS), T. Trnski, S. Hannam (AIM), D. Catania and M. Hoang (CAS), H. Kawase (CMNH), A. Stewart (NMNZ), J. Williams, S. Raredon, K. Murphy, and D. Pitassy (USNM) for providing opportunities to examine specimens. This study was supported in part by a Grant-in-Aid from the Japan Society for the Promotion of Science for JSPS Fellows (DC1: 19J21103); JSPS KAKENHI Grant Numbers 20H03311 and 21H03651; the JSPS Core-to-Core Program: B Asia-Africa Science Platforms (CREPSUM JPJSCCB2020009); the "Biological Properties of Biodiversity Hotspots in Japan" project of the National Museum of Nature and Science, Tsukuba, Japan; and "Establishment of Glocal Research and Education Network in the Amami Islands" project of Kagoshima University adopted by the Ministry of Education, Culture, Sports, Science and Technology, Japan. KWC acknowledges financial support from Texas A\&M Agrilife Research (Hatch TEX09452), and the Biodiversity Research and Teaching Collections at Texas A\&M University (BRTC publication 1643).

\section{References}

Briggs JC (1955) A monograph of the clingfishes (order Xenopterygii) Stanford Ichthyological Bulletin 6: 1-244.

Conway KW, Kim D, Rüber L, Espinosa Pérez HS, Hastings PA (2017a) Molecular systematics of the New World clingfish genus Gobiesox (Teleostei: Gobiesocidae) and the origin of a freshwater clade. Molecular Phylogenetics and Evolution 112: 138-147. https://doi.org/10.1016/j.ympev.2017.04.024

Conway KW, King CD, Summers AP, Kim D, Hastings PA, Moore GI, Iglesias SP, Erdmann MV, Short G, Fujiwara K, Trnski T, Voelker G, Rüber L (2020) Molecular phylogenetics of the clingfishes (Teleostei: Gobiesocidae)-implications for classification. Copeia 108: 886-906. https://doi.org/10.1643/CI2020054

Conway KW, Stewart AL, King C (2017b) A new species of the clingfish genus Trachelochismus from bay and estuarine areas of New Zealand (Teleostei: Gobiesocidae). Zootaxa 4319: 531-549. https://doi.org/10.11646/zootaxa.4319.3.6

Conway KW, Stewart AL, Summers AP (2018a) A new genus and species of clingfish from the Rangitāhua Kermadec Islands of New 
Zealand (Teleostei, Gobiesocidae). ZooKeys 786: 75-104. https:// doi.org/10.3897/zookeys.786.28539

Conway KW, Stewart AL, Summers AP (2018b) A new species of sea urchin associating clingfish of the genus Dellichthys from New Zealand (Teleostei, Gobiesocidae). ZooKeys 740: 77-95. https:// doi.org/10.3897/zookeys.740.22712

Fricke R, Chen JN, Chen WJ (2016) New case of lateral asymmetry in fishes: A new subfamily, genus and species of deep water clingfishes from Papua New Guinea, western Pacific Ocean. Comptes Rendus Biologies 340: 47-62. https://doi.org/10.1016/j. crvi.2016.11.002

Fricke R, Eschmeyer WN, Van der Laan R (2021) Eschmeyer's cata$\log$ of fishes: genera, species, references. http://researcharchive. calacademy.org/research/ichthyology/catalog/fishcatmain.asp. Accessed on: 2021-1-26.

Fujiwara K, Motomura H (2018a) Revised diagnosis and first Northern Hemisphere records of the rare clingfish Lepadichthys akiko (Gobiesocidae: Diademichthyinae). Species Diversity 23: 87-93. https://doi.org/10.12782/specdiv.23.87

Fujiwara K, Motomura H (2018b) A new species, Propherallodus longipterus, from the Philippines and redescription of P. briggsi Shiogaki and Dotsu 1983 (Gobiesocidae: Diplocrepinae). Ichthyological Research 66: 35-48. https://doi.org/10.1007/s10228-0180645-4

Fujiwara K, Motomura H (2019) Kopua minima (Döderlein 1887), a senior synonym of $K$. japonica Moore, Hutchins and Okamoto 2012, and description of a new species of Aspasma (Gobiesocidae). Ichthyological Research 67: 50-67. https://doi.org/10.1007/ s10228-019-00701-0

Fujiwara K, Motomura H (2020) Revised diagnosis of the rare clingfish Kopua nuimata (Gobiesocidae) with notes on fresh coloration and first Australian record. Species Diversity 25: 49-54. https:// doi.org/10.12782/specdiv.25.49

Hardy GS (1984) A new genus and species of deepwater clingfish (family Gobiesocidae) from New Zealand. Bulletin of Marine Science 34: 244-247.

Hastings PA, Conway KW (2017) Gobiesox lanceolatus, a new species of clingfish (Teleostei: Gobiesocidae) from Los Frailes submarine canyon, Gulf of California, Mexico. Zootaxa 4221: 393400. https://doi.org/10.11646/zootaxa.4221.3.8

Jordan DS, Fowler HW (1902) A review of the cling-fishes (Gobiesocidae) of the waters of Japan. Proceedings of the United States National Museum 25: 413-416. https://doi.org/10.5479/si.00963 801.25-1291.413

Sabaj MH (2020) Codes for natural history collections in ichthyology and herpetology. Copeia 108: 593-669. https://oi.org/10.1643/ ASIHCODONS2020

Saruwatari T, Lopez JA, Pietsch TW (1997) Cyanine Blue: a versatile and harmless stain for specimen observation. Copeia 1997: 840-841.

Shiogaki M, Dotsu Y (1983) Two new genera and two new species of clingfishes from Japan, with comments on head sensory canals of the Gobiesocidae. Japanese Journal of Ichthyology 30: 111-121.

Stewart AL (2015) 218 Family Gobiesocidae. In: Roberts CD, Stewart AL, Struthers CD (Eds.) The Fishes of New Zealand. Volume Four. Systematic Accounts. Te Papa Press, Wellington, New Zealand,1539-1555.

Weber M (1913) Die Fische der Siboga-Expedition. E.J. Brill, Leiden, Netherlands, $710 \mathrm{pp}$.

Wessel P, Smith WHF (1996) A global self-consistent, hierarchical, high-resolution shoreline database. Journal of Geophysical Research 101 (B4): 8741-8743. 